\title{
Predictors and prognostic implications of clinical decisions in patients with primary high-risk non-muscle-invasive bladder cancer - results of a cross country retrospective study
}

\begin{abstract}
S. POLETAJEW ${ }^{1, \star}$, R. BIERNACKI ${ }^{2}$, P. BURACZYNSKI ${ }^{3}$, J. CHOJNACKI ${ }^{4}$, S. CZARNIECKI ${ }^{5}$, D. GAJEWSKA ${ }^{6}$, T. POHABA ${ }^{7}$, J. SONDKA-MIGDALSKA ${ }^{8}$, M. SKRZYPCZYK ${ }^{4}$, T. SUCHOJAD ${ }^{9}$, D. WOJTKOWIAK ${ }^{10}$, B. ZAFOREMSKI ${ }^{11}$, L. ZAPALA ${ }^{12}$, A. ZEMLA ${ }^{13}$, P. RADZISZEWSKI ${ }^{1}$

${ }^{1}$ Department of Urology, Medical University of Warsaw, Warsaw, Poland; ${ }^{2}$ Department of Urology, The Regional Hospital, Leszno, Poland; ${ }^{3}$ Department of Urology, Medical University of Lublin, Lublin, Poland; ${ }^{4}$ Department of Urology, Center of Postgraduate Medical Education, Warsaw, Poland; ${ }^{5}$ Department of Urology, John Paul II Western Hospital, Grodzisk Mazowiecki, Poland; ${ }^{6}$ Department of Urology and Urological Oncology, Pomeranian Medical University, Szczecin, Poland; ${ }^{7}$ Department of Urology, The Regional Multidisciplinary Hospital, Jastrzebie Zdroj, Poland; ${ }^{8}$ First Department of Urology, Military Medical Academy University Teaching Hospital - Central Veterans Hospital, Lodz, Poland; ${ }^{\circ}$ Departament of Urology, Provincial Specialist Hospital, Czerwona Gora, Poland; ${ }^{10}$ Department of Urology, Regional Hospital Centrum, Jelenia Gora, Poland; ${ }^{11}$ Department of Urology and Oncological Urology, John Paul II Subcarpatian Provincial Hospital, Krosno, Poland; ${ }^{12}$ Department of Urology, Multidisciplinary Hospital Warsaw-Miedzylesie, Warsaw, Poland; ${ }^{13}$ Department of Urology and Urological Oncology, Lowersilesian Multidisciplinary Hospital, Wroclaw, Poland
\end{abstract}

*Correspondence: slawomir.poletajew@wum.edu.pl

Received February 17, 2017 / Accepted May 9, 2017

Adjuvant diagnostic and therapeutic procedures are available to reduce the risk of recurrence or progression in patients with high-risk non-muscle-invasive bladder cancer (NMIBC). However, their indications and efficacy remain a matter of debate. The aim of this study was to analyze therapeutic decisions in patients with primary high-risk NMIBC and to analyze the adherence to clinical guidelines in this field.

545 consecutive patients, aged a median of 70.3 years, diagnosed with primary high-risk NMIBC in thirteen urological institutions, were enrolled into this retrospective study. Diagnostic and therapeutic decisions after transurethral resection (TUR) were recorded, and predictive factors were analyzed.

Restaging TUR was offered to 260 patients (47.7\%), up-front intravesical Bacillus Calmette-Guerin (BCG) therapy to 74 patients (13.6\%), immediate radical cystectomy to 38 patients $(7.0 \%)$, and intravesical chemotherapy with the maintenance therapy to 12 patients $(2.2 \%)$. No additional procedure was performed in 161 patients $(29.5 \%)$. The strongest predictive factor for restaging TUR was G3 or high-grade cancer (RR 1.68, p<0.01), for upfront BCG therapy it was carcinoma in situ (RR 3.20, $\mathrm{p}=0.01$ ), for immediate cystectomy it was stage T1 tumor (RR 3.71, $\mathrm{p}<0.01$ ), for no additional procedures it was G2 or low-grade cancer (RR 2.18, $\mathrm{p}<0.01$ ).

Clinical management of patients with high-risk NMIBC is suboptimal and not standardized. As this can directly influence patients' survival, urgent improvement of urological care in this field should be considered.

Key words: bladder cancer, clinical decision-making, multicenter study, survival

In patients with non-muscle-invasive bladder cancer (NMIBC), transurethral resection of the bladder tumor (TUR) remains the critical step in disease management [1]. However, there is a subgroup of patients, in whom the probability of disease recurrence and progression during the follow-up is particularly high, reaching $78 \%$ and $45 \%$ at five years, respectively [2]. Experts of the European Association of Urology define this high-risk group as patients with stage T1 tumors, G3 tumors, high-grade tumors or carcinoma in situ (Cis) [3].
The primary goals of TUR are complete removal of the tumor and proper pathological staging [3]. They both may require second or restaging TUR, especially in high-risk patients. Once proper pathological staging is completed, various therapeutic procedures are believed to reduce the risk of disease recurrence, including intravesical chemotherapy, intravesical Bacillus Calmette-Guerin (BCG) immunotherapy, and immediate radical cystectomy. To date, in patients with high-risk NMIBC, there are controversies regarding indications for restaging TUR, indications and 
safety of BCG therapy, as well as qualification for immediate radical cystectomy.

The aim of the study was to describe therapeutic decisions in patients with primary high-risk NMIBC and to analyze the adherence to clinical guidelines in this field.

\section{Patients and methods}

Patients. 545 consecutive patients, diagnosed with primary high-risk non-muscle-invasive urothelial bladder carcinoma in thirteen Central European urological institutions, were enrolled into this study. All patients underwent TUR. The definition of high-risk cancer was adopted from the Expert Panel of the European Association of Urology [3], and covered stage T1 cancer according to 2009 TNM staging classification [4], grade G3 cancer according to 1973 WHO grading classification [5], high-grade cancer according to 2004 WHO/ISUP grading classification [6], or Cis. The exclusion criteria were as follows: muscle-invasive disease, pathological stage Tx disease (primary tumor cannot be assessed), recurrent urothelial cancer, age $<18$ years.

Medical records of all patients were retrospectively analyzed with special attention paid to the further diagnostic and therapeutic procedures and their predictive factors. The primary end-point of the study was the first clinical decision after the diagnosis of high-risk NMIBC, including restaging TURBT, intravesical chemotherapy with the maintenance, intravesical BCG immunotherapy with or without the maintenance, immediate radical cystectomy, or observation only. Moreover, an attempt to identify factors predicting the management decisions was undertaken.

- Restaging TUR

- Intravesical BCG immunotherapy

- Radical cystectomy

- Intravesical chemotherapy with the maintenance therapy

- Observation only

OVERALL $(\mathrm{N}=545)$ $48 \%$ $14 \% \quad 7 \% 2 \% \quad 30 \%$

T1 TUMORS $(\mathrm{N}=516)$ $13 \% \quad 7 \% 2 \% \quad 30 \%$

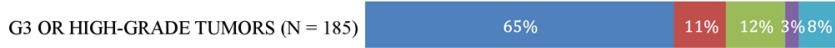

$$
\begin{array}{lll}
\operatorname{CIS}(\mathrm{N}=15) & 80 \% & 13 \% 7
\end{array}
$$

Figure 1. Clinical decisions after the diagnosis of high-risk NMIBC.
This was a retrospective non-interventional study; the Ethical Board approval was waived according to institutional regulations. Simultaneously, the study conformed to the provisions of the Declaration of Helsinki.

\section{Results}

A basic characteristic of the study group is presented within Table 1. Among patients with G3 or high-grade tumors, there were 26 cases of stage Ta tumors and 159 cases of stage T1 tumors. Among 15 patients with Cis, only 2 patients had isolated primary Cis, while in the remaining cases Cis was concomitant to papillary high-risk tumors.

Restaging TUR was performed in 260 patients (47.7\%), including $47.3 \%$ of stage T1 cases, $65.4 \%$ of G3 or high-grade cases and $80 \%$ of Cis cases. Simultaneously, BCG therapy was initiated in 74 patients (13.6\%), 38 patients $(7.0 \%)$ were qualified for radical cystectomy, while 12 patients $(2.2 \%)$ received intravesical chemotherapy with the maintenance therapy. No additional staging or therapeutic procedure was offered to 161 patients (29.5\%). This group was included into a follow-up with regular cystoscopies. Figure 1 presents the first clinical decision after the diagnosis.

The analysis of potential predictors of clinical decisions revealed that restaging TUR was offered mainly for G3 or high-grade cancer patients (RR 1.68, $\mathrm{p}<0.01$ ); upfront BCG therapy for patients with Cis ( $R R 3.20, p=0.01)$; immediate cystectomy for patients with T1 tumors (RR 3.71, $\mathrm{p}<0.01$ ), with the exception of those aged $>70$ years (RR $0.47, p=0.02$ ); while the risk of no additional treatment was the highest among patients with T1 G2 or T1 low-grade cancer (RR 2.18, $\mathrm{p}<0.01)$ and the lowest among patients with G3 or highgrade cancer (RR $0.45, \mathrm{p}<0.01$ ). Detailed data regarding the predictors of qualification to staging and therapeutic procedures or observation only depending on clinical settings is presented in Table 2.

\section{Discussion}

Bladder cancer is the most common neoplasm of the urinary system. In Europe, the highest age-standardized death rates are reported for Poland and Spain [7]. A recent Polish analysis revealed that one of the underlying reasons could be a particularly high incidence of high-risk NMIBC [8]. Being aware of the significant risk of disease recurrence and progression in this group of patients, we decided to

Table 1. Basic characteristics of the study group.

\begin{tabular}{|c|c|c|c|c|}
\hline & Overall & T1 tumors & G3 or HG tumors & Cis \\
\hline Number of patients & 545 & 516 & 185 & 15 \\
\hline Mean age of patients & 70.3 & 70.1 & 71.8 & 72.7 \\
\hline Male to female ratio & $3.7: 1$ & $3.6: 1$ & $4.4: 1$ & $2.8: 1$ \\
\hline $\begin{array}{l}\text { Number (percentage) of patients receiving immediate single } \\
\text { postoperative intravesical instillation of chemotherapy }\end{array}$ & $74(13.6 \%)$ & $65(12.6 \%)$ & $38(20.5 \%)$ & $2(13.3 \%)$ \\
\hline
\end{tabular}


Table 2. Relative risk values for qualification to staging and therapeutic procedures or observation only depending on clinical settings.

\begin{tabular}{|c|c|c|c|c|c|c|c|c|c|c|c|c|}
\hline \multirow{2}{*}{$\begin{array}{l}\text { Procedures } \\
\backslash \\
\text { Potential predic- } \\
\text { tive factors }\end{array}$} & \multicolumn{3}{|c|}{ Restaging TUR } & \multicolumn{3}{|c|}{$\begin{array}{l}\text { Intravesical BCG } \\
\text { immunotherapy }\end{array}$} & \multicolumn{3}{|c|}{ Immediate radical cystectomy } & \multicolumn{3}{|c|}{ Observation only } \\
\hline & $\begin{array}{c}\% \text { of } \\
\text { patients }^{*}\end{array}$ & RR & p-value & $\begin{array}{c}\% \text { of } \\
\text { patients }^{*}\end{array}$ & RR & p-value & $\begin{array}{c}\% \text { of } \\
\text { patients }^{*}\end{array}$ & $\mathbf{R R}$ & p-value & $\begin{array}{c}\% \text { of } \\
\text { patients }^{*}\end{array}$ & RR & p-value \\
\hline $\begin{array}{l}\text { TaG3 or Ta } \\
\text { high-grade tumor }\end{array}$ & $57.7 \%$ & 1.20 & 0.00 & $20.0 \%$ & 1.22 & 0.91 & $4.2 \%$ & 0.55 & 0.16 & $34.6 \%$ & 0.98 & 0.94 \\
\hline $\begin{array}{l}\mathrm{T} 1 \mathrm{G} 2 \text { or } \mathrm{T} 1 \\
\text { low-grade tumor }\end{array}$ & $39.4 \%$ & 0.60 & 0.00 & $15.9 \%$ & 1.42 & 0.13 & $4.4 \%$ & 0.34 & 0.00 & $43.5 \%$ & 2.18 & 0.00 \\
\hline $\begin{array}{l}\text { T1G3 or T1 } \\
\text { high-grade tumor }\end{array}$ & $67.5 \%$ & 1.65 & 0.00 & $10.4 \%$ & 0.65 & 0.08 & $15.0 \%$ & 3.71 & 0.00 & $17.2 \%$ & 0.40 & 0.00 \\
\hline Any $\mathrm{T} 1$ tumor & $48.1 \%$ & 0.85 & 0.00 & $13.9 \%$ & 0.75 & 0.78 & $7.6 \%$ & 2.05 & 0.13 & $35.4 \%$ & 1.06 & 0.81 \\
\hline $\begin{array}{l}\text { Any G3 or } \\
\text { high-grade tumor }\end{array}$ & $66.3 \%$ & 1.68 & 0.00 & $11.1 \%$ & 0.71 & 0.15 & $12.9 \%$ & 2.97 & 0.00 & $19.6 \%$ & 0.45 & 0.00 \\
\hline Cis & $81.3 \%$ & 1.70 & 0.03 & $42.9 \%$ & 3.20 & 0.01 & $7.1 \%$ & 0.99 & 0.99 & $12.5 \%$ & 0.35 & 0.05 \\
\hline Female sex & $48.2 \%$ & 0.99 & 0.87 & $11.6 \%$ & 0.78 & 0.59 & $7.2 \%$ & 1.00 & 0.99 & $34.8 \%$ & 0.98 & 0.90 \\
\hline Male sex & $48.8 \%$ & 1.01 & 0.91 & $14.9 \%$ & 1.28 & 0.37 & $7.2 \%$ & 1.00 & 0.99 & $35.5 \%$ & 1.02 & 0.90 \\
\hline Age $>70$ years & $51.1 \%$ & 1.11 & 0.32 & $12.6 \%$ & 0.80 & 0.36 & $4.6 \%$ & 0.47 & 0.02 & $36.1 \%$ & 1.04 & 0.72 \\
\hline $\begin{array}{l}\text { Abnormal BMI } \\
\left(<18 \text { or }>25 \mathrm{~kg} / \mathrm{m}^{2}\right)\end{array}$ & $42.9 \%$ & 1.14 & 0.16 & $17.5 \%$ & 1.29 & 0.23 & $5.1 \%$ & 0.40 & 0.04 & $38.9 \%$ & 1.20 & 0.18 \\
\hline $\begin{array}{l}\text { Anaemia (haemo- } \\
\text { globin concentra- } \\
\text { tion }<12 \mathrm{mg} \% \text { ) }\end{array}$ & $43.5 \%$ & 0.87 & 0.45 & $9.7 \%$ & 0.63 & 0.27 & $11.6 \%$ & 1.93 & 0.04 & $42.1 \%$ & 1.25 & 0.09 \\
\hline
\end{tabular}

*The percentage of patients with predictive factor present who underwent the procedure. BMI - body mass index; RR - relative risk.

perform a multi-institutional analysis of clinical decisions made in patients with primary high-risk NMIBC with the special attention paid to their predictors. Our study showed that clinical management in this group of patients is suboptimal, with restaging TUR performed in less than $50 \%$ of patients and almost $30 \%$ of patients with no adjuvant procedures offered. To our knowledge, this is first such analysis in the region of Central Europe. It identifies potential reasons for unsatisfactory treatment outcomes in bladder cancer patients and indicates the need for urgent improvement in everyday clinical practice.

Almost one third of patients in the present cohort was treated out of clinical guidelines. They were either qualified for intravesical chemotherapy, which is not recommended in high-risk patients, or they were included into an observational protocol only after initial TUR with no adjuvant treatment. In the study by Witjes et al., the percentage of highrisk patients who received intravesical chemotherapy as the sole treatment mode or who had not received any additional procedure after TURBT were $12.5 \%$ and $9 \%$, respectively [9]. While all these numbers are clinically very relevant, they are particularly alarming in the present study. Among Polish patients with primary high-risk NMIBC, 30\% undergo TUR followed by observation only. Even in the subgroup of patients with the high-grade T1 disease, this percentage is still as high as $17 \%$. As stated previously, in high-risk patients the five-year risk of progression reaches $45 \%$ and this scenario seems probable especially in patients who are staged incorrectly or who do not receive any further treatment [2]. On the other hand, there were many cases of T1 low-grade or T1 G2 cancers in our cohort. These diagnoses were the most important predictors of the decision of performing no additional procedure after the initial TUR. The histological diagnosis of low grade T1 disease is controversial, while the data concerning prognosis and optimal treatment are lacking. Even though the indications for restaging TUR are a matter of debate and the availability of BCG treatment was limited in previous years, it seems incomprehensible that $30 \%$ of patients did not receive any further treatment. The underestimation of malignant potential of high-risk NMIBC can be one of the triggers for shorter survival among Polish patients as compared to other European countries [7].

In patients with high-risk NMIBC, restaging TUR allows to diagnose residual disease in up to $55 \%$ of stage $\mathrm{T} 1$ cases and $41 \%$ of stage Ta cases [3]. Furthermore, it ensures the proper staging and improves oncological outcomes [10]. According to the 2016 clinical guidelines of the European Association of Urology, restaging TUR is indicated in all patients with stage T1 tumors, poorly differentiated tumors (high-grade or G3), incomplete resection or when no detrusor muscle tissue is sampled [3]. However, in our study, we noticed that restaging TUR was offered only to $48 \%$ of patients. Our results are in concordance with data previously published by Gontero et al. In their study, presenting real-life patterns of care in Italian patients with high-risk NMIBC, the authors found that restaging TUR was performed in $49.2 \%$ of cases [11]. This represents a high level of non-adherence to clinical guidelines. Potentially low rate of restaging TUR can result from doubts among clinical practitioners regarding the indications for the procedure. Gontero et al. recently showed that 
restaging TUR can be omitted in T1 patients if the muscle is present in the specimen with no influence on patients' survival [12]. Consequently, a consensus document reviewed and endorsed by Bladder Cancer Canada, Canadian Urologic Oncology Group, and Canadian Urological Association does not recommend routine restaging TUR in patients staged TaHG and states that it can be omitted in selected patients staged T1 when muscle is sampled [13]. However, a recent retrospective analysis by Gotto et al. showed that restaging TUR in patients with high-grade T1 tumors has positive impact on five-year overall survival and is underused in Canada [14]. Finally, it is under the debate who should undergo restaging TUR and who can safely avoid this procedure. Unfortunately, the number of randomized controlled studies presenting the clinical value of restaging TUR is very limited and the available evidence is based mainly on retrospective observational studies.

Intravesical BCG immunotherapy is regarded as a standard adjuvant treatment in patients with high-risk NMIBC that improves the recurrence-free survival [3]. In our cohort, BCG therapy was the first therapeutic decision in almost $14 \%$ of patients. The probability of receiving BCG therapy was the highest among patients with Cis. Moreover, one can suspect that the majority of patients undergoing restaging TUR was also eventually qualified for BCG immunotherapy, increasing the final rate of BCG therapy up to about $60 \%$ of the studied patients. At this point, our results are again comparable to these presented by Gontero et al., who noticed the use of BCG therapy in $60.5 \%$ of high-risk cases [11]. On the other hand, Nielsen et al. presented a $91 \%$ rate of BCG therapy in patients with high-grade NMIBC. However, this was a survey study with a very low response-rate, limiting its reliability [15]. The problem of underuse of BCG therapy is a well-known phenomenon in urology. There are several possible reasons, however, that were never objectively assessed. The most important two issues are probably the risk of BCG-related toxicity and the reduced availability of BCG strains in recent years. The EORTC study revealed that almost $70 \%$ of patients receiving BCG therapy experience at least one side effect related to the treatment. On the other hand, in the same study, toxicity was the rarest reason for treatment discontinuation [16]. To date, the influence of safety profile on decision of patients and urologists regarding BCG therapy was not assessed.

Apart from qualification, also the schedule of the BCG therapy is of great clinical importance. While this was not assessed within the present study, a recent international analysis by Witjes et al. showed that only $50 \%$ of patients with high-risk NMIBC in Europe, Canada and United States received BCG therapy with maintenance [9]. Moreover, an analysis of the SEER database indicated that $99 \%$ of all patients with bladder cancer do not receive more than 6 instillations [17].

The decision of performing radical cystectomy in patients with high-risk NMIBC is difficult to undertake. There is no fully reliable predictive tool of progression to muscle-invasive disease, so the risk of overtreatment cannot be ignored in any case. Additionally, there are studies showing a longterm survival of patients operated at the time of progression comparable to that in patients undergoing immediate surgery $[18,19]$. In our study, $7 \%$ of patients were qualified for radical cystectomy, with the extensive T1 high-grade or G3 histopathology being the most common indication. The most important factors for disqualification from the surgery were abnormal body mass index (BMI) value and elder age defined as the age $>70$ years. Both of these conditions are considered risk factors of post-radical cystectomy complications [20-23]. Surprisingly, low haemoglobin concentration was found to be predictor of radical cystectomy in the current cohort, despite elsewhere demonstrated negative impact on postoperative survival $[24,25]$. An analysis of the SEER database by Canter et al. revealed that less than $5 \%$ of patients with high-grade $\mathrm{T} 1$ disease underwent immediate cystectomy. Moreover, early radical surgery had no effect on cancer-specific survival [26]. Witjes et al. in their international individual patient data survey noticed that immediate radical cystectomy was performed in $9 \%$ of patients with high-risk NMIBC, and this was more common in academic centers [9]. Based on these data, it seems that early radical cystectomy performed at the time of BCG failure is definitively more common than immediate radical cystectomy performed directly after initial diagnosis of NMIBC. However, exact data regarding this issue are lacking.

Our study is not free of limitations. As the study's end-point was the first clinical decision, we did not consider the results of restaging TUR or cystectomy and their clinical sequelae. Hence, it is possible that there are under staged patients with muscle-invasive bladder cancer in our cohort. At the same time, patients who underwent restaging TUR followed by intravesical BCG immunotherapy are not recorded with the second intervention. Furthermore, due to the retrospective nature of our analysis, we were not able to incorporate patients individual risk of recurrence and progression into our considerations, while this data could significantly influence the clinical decisions. Simultaneously, we present a representative homogenous cohort of consecutive patients with primary high-risk NMIBC. While there were thirteen urological institutions involved, the risk of bias related to regional trends of care is assessed as minimal.

In conclusion: clinical management in patients with highrisk NMIBC is not uniform. The decisions taken after the diagnosis seem suboptimal in many cases, what can directly influence patient survival. Clinical practice in Europe seems unified in terms of the use of restaging TUR and radical cystectomy. However, in Central Europe significantly more patients receive no additional treatment after initial TUR, what can lead to understating and lower survival rates in the region. While the adherence to clinical guidelines should improve, the urological community is in need of high-level evidence on the indications for restaging TURBT and radical cystectomy in NMIBC patients. 


\section{References}

[1] BABJUK M. Optimized management in patients with bladder cancer. Cent European J Urol 2015; 68: 15-6. doi: 10.5173/ceju.2015.01.e93

[2] SYLVESTER RJ, VAN DER MEIJDEN AP, OOSTERLINCK W, WITJES JA, BOUFFIOUX C et al. Predicting recurrence and progression in individual patients with stage Ta T1 bladder cancer using EORTC risk tables: a combined analysis of 2596 patients from seven EORTC trials. Eur Urol 2006; 49:466-465.

[3] BABJUK M, BOHLE A, BURGER M, CAPOUN O, COHEN D et al. EAU Guidelines on Non-Muscle-invasive Urothelial Carcinoma of the Bladder: Update 2016. Eur Urol 2017; 71: 447-461. doi: 10.1016/j.eururo.2016.05.041

[4] SOBIN LH, GOSPODAROWICZ MK, WITTEKIND C (Eds.). TNM classification of malignant tumours, 7th Edition. Wiley-Blackwell, Chichester 2009, p 332. ISBN 978-14443-3241-4.

[5] MOSTOFI FK, SOBIN LH, TORLONI H (Eds.). Histological typing of urinary bladder tumours. World Health Organization, Geneva 1973. ISBN 978-9-2417-6010-2, accessed at http://www.who.int/iris/handle/10665/41533

[6] EBLE JN, SAUTER G, EPSTEIN JI, SESTERHENN IA (Eds.). World Health Organization Classification of Tumours. Pathology and Genetics of Tumours of the Urinary System and Male Genital Organs. IARC Press, Lyon 2004, p. 369. ISBN 9283224124

[7] BOSETTI C, BERTUCCIO P, CHATENOUD L, NEGRI E, LA VECCHIA C et al. Trends in mortality from urologic cancers in Europe, 1970-2008. Eur Urol 2011; 60: 1-15. doi: 10.1016/j.eururo.2011.03.047

[8] POLETAJEW S, BIERNACKI R, BURACZYNSKI P, CHOJNACKI J, CZARNIECKI S et al. Stage of bladder cancer in Central Europe - Polish perspective. Neoplasma 2016; 63: 642-647. doi: 10.4149/neo $2016 \quad 420$

[9] WITJES JA, PALOU J, SOLOWAY M, LAMM D, KAMAT $\mathrm{AM}$ et al. Current clinical practice gaps in the treatment of intermediate- and high-risk non-muscle-invasive bladder cancer (NMIBC) with emphasis on the use of bacillus Calmette-Guerin (BCG): results of an international individual patient data survey (IPDS). BJU Int 2013; 112: 742-750. doi: $10.1111 /$ bju. 12012

[10] DIVRIK RT, SAHIN AF, YILDIRIM U, ALTOK M, ZORLU F. Impact of routine second transurethral resection on the longterm outcome of patients with newly diagnosed pT1 urothelial carcinoma with respect to recurrence, progression rate, and disease-specific survival: a prospective randomised clinical trial. Eur Urol 2010; 58: 185-190. doi: 10.1016/j.eururo.2010.03.007

[11] GONTERO P, ODERDA M, ALTIERI V, BARTOLETTI $\mathrm{R}, \mathrm{CAI} \mathrm{T}$ et al. Are referral centers for non-muscle-invasive bladder cancer compliant to EAU guidelines? A report from the vesical antiblastic therapy Italian study. Urol Int 2011; 86: 19-24. doi: $10.1159 / 000321926$

[12] Gontero P, Sylvester R, Pisano F, Joniau S, Oderda M, et al. The impact of re-transurethral resection on clinical outcomes in a large multicentre cohort of patients with T1 highgrade/Grade 3 bladder cancer treated with bacille CalmetteGuerin. BJU Int. 2016;118(1):44-52.
[13] KASSOUF W, APRIKIAN A, BLACK P, KULKARNI G, IZAWA $J$ et al. Recommendations for the improvement of bladder cancer quality of care in Canada: A consensus document reviewed and endorsed by Bladder Cancer Canada (BCC), Canadian Urologic Oncology Group (CUOG), and Canadian Urological Association (CUA), December 2015. Can Urol Assoc J 2016; 10: E46-80. doi: 10.5489/cuaj.3583

[14] GOTTO GT, SHEA-BUDGELL MA, DEAN RUETHER J. Low compliance with guidelines for re-staging in high-grade T1 bladder cancer and the potential impact on patient outcomes in the province of Alberta. Can Urol Assoc J 2016; 10: 33-38. doi: $10.5489 /$ cuaj. 3143

[15] NIELSEN ME, SMITH AB, PRUTHI RS, GUZZO TJ, AMIEL $G$ et al. Reported use of intravesical therapy for nonmuscle-invasive bladder cancer (NMIBC): results from the Bladder Cancer Advocacy Network (BCAN) survey. BJU Int 2012; 110: 967-972. doi: 10.1111/j.1464-410X.2012.11060.x

[16] BRAUSI M, ODDENS J, SYLVESTER R, BONO A, VAN DE BEEK $C$ et al. Side effects of Bacillus Calmette-Guerin (BCG) in the treatment of intermediate- and high-risk Ta, T1 papillary carcinoma of the bladder: results of the EORTC genito-urinary cancers group randomised phase 3 study comparing one-third dose with full dose and 1 year with 3 years of maintenance BCG. Eur Urol 2014; 65: 69-76. doi: $\underline{10.1016 / j . e u r u r o .2013 .07 .021}$

[17] CHAMIE K, SAIGAL CS, LAI J, HANLEY JM, SETODJI $\mathrm{CM}$ et al. Compliance with guidelines for patients with bladder cancer: variation in the delivery of care. Cancer 2011; 117: 5392-5401. doi: $10.1002 / \mathrm{cncr} .26198$

[18] MARGEL D, TAL R, GOLAN S, KEDAR D, ENGELSTEIN $\mathrm{D}$ et al. Long-term follow-up of patients with Stage T1 high-grade transitional cell carcinoma managed by Bacille Calmette-Guerin immunotherapy. Urology 2007; 69: 78-82.

[19] PANSADORO V, EMILIOZZI P, DE PAULA F, SCARPONE P, PANSADORO A et al. Long-term follow-up of G3T1 transitional cell carcinoma of the bladder treated with intravesical bacille Calmette-Guerin: 18-year experience. Urology 2002; 59: 227-231.

[20] LEE CT, DUNN RL, CHEN BT, JOSHI DP, SHEFFIELD J et al. Impact of body mass index on radical cystectomy. J Urol 2004; 172: 1281-1285.

[21] NOVOTNY V, ZASTROW S, KOCH R, WIRTH MP. Radical cystectomy in patients over 70 years of age: impact of comorbidity on perioperative morbidity and mortality. World J Urol 2012; 30: 769-776. doi: 10.1007/s00345-011-0782-0

[22] ROGHMANN F, SUKUMAR S, RAVI P, TRINH VQ, MESKAWI $M$ et al. Radical cystectomy in the elderly: national trends and disparities in perioperative outcomes and quality of care. Urol Int 2014; 92: 27-34. doi: 10.1159/000353091

[23] SVATEK RS, FISHER MB, WILLIAMS MB, MATIN SF, KAMAT AM et al. Age and body mass index are independent risk factors for the development of postoperative paralytic ileus after radical cystectomy. Urology 2010; 76: 14191424. doi: 10.1016/j.urology.2010.02.053

[24] HARA T, MATSUYAMA H, KAMIRYO Y, HAYASHIDA S, YAMAMOTO $\mathrm{N}$ et al. Use of preoperative performance status and hemoglobin concentration to predict overall survival for patients aged $\geq 75$ years after radical cystectomy for treatment of bladder cancer. Int J Clin Oncol 2016; 21: 139-147. doi: 10.1007/s10147-015-0857-9 
[25] SEJIMA T, MORIZANE S, YAO A, ISOYAMA T, SAITO M et al. Prognostic impact of preoperative hematological disorders and a risk stratification model in bladder cancer patients treated with radical cystectomy. Int J Urol 2014; 21: 52-57. doi: $10.1111 /$ iju. 12161
[26] CANTER D, EGLESTON B, WONG YN, SMALDONE MC, SIMHAN J et al. Use of radical cystectomy as initial therapy for the treatment of high-grade T1 urothelial carcinoma of the bladder: a SEER database analysis. Urol Oncol 2013; 31: 866-870. doi: 10.1016/j.urolonc.2011.07.009 